\title{
Pelatihan Media Belajar Digital Bagi Guru SDIT Mutiara Pariaman di Era New Normal
}

\author{
Devi Rusli \\ Fakultas Pendidikan Psikologi dan Kesehatan, Universitas Negeri Padang \\ *e-mail: devirusli@fip.unp.ac.id ${ }^{1}$
}

\begin{abstract}
The Covid 19 pandemic caused a change in the world of education without exception in student learning in school. Teachers need learning media based on digital technology to support the success of the teaching and learning process both online and offline (face-to-face). While the utilization of other learning media such as LCD, youtube videos or videos made by teachers, and others are still very minimal. Related to the problem of lack of literacy and teacher expertise in making learning media, it is necessary to take a psychological approach to increase knowledge / insight and teacher skills in using learning media. The solution offered is to improve literacy (through counseling) and teacher expertise (through training) to make digital learning media fun for students.
\end{abstract}

Keywords: Training, Digital Learning Media, Pearl SDIT

\begin{abstract}
Abstrak
Pandemi Covid 19 menyebabkan perubahan dalam dunia pendidikan tanpa pendidikan dalam pembelajaran siswa di sekolah. Guru memerlukan media pembelajaran yang berbasis teknologi digital guna mendukung keberhasilan proses belajar mengajar baik secara online maupun offline (tatap muka). Sementara pemanfaatan media belajar lainnya seperti LCD, video youtube atau video yang dibuat oleh guru, dan lain-lain masih sangat minim. Terkait dengan masalah minimnya literasi dan keahlian guru dalam membuat media pembelajaran, maka perlu dilakukan pendekatan psikologis untuk menambah pengetahuan/wawasan dan keterampilan guru dalam menggunakan media belajar. Solusi yang ditawarkan adalah peningkatan literasi (melalui penyuluhan) dan keahlian (melalui pelatihan) guru membuat media belajar digital yang menyenangkan bagi siswa.
\end{abstract}

Kata kunci: Pelatihan, Media belajar digital, SDIT Mutiara

\section{PENDAHULUAN}

Akibat pandemi Covid 19 sejak tahun 2019 membawa dampak yang luas dalam kehidupan termasuk pendidikan. Pelaksanaan sistem pembelajaran daring (dalam jaringan) di Indonesia selama masa pembatasan sosial di sekolah masih kurang optimal. Terdapat beberapa faktor penyebabnya terutama mengenai akses internet. Beberapa daerah di Indonesia belum memiliki akses internet yang baik yang sangat mendukung proses pembelajaran daring (Sandi, 2020; Zahralubis, 2020). Disamping itu, kemampuan orangtua dalam mendampingi anak-anak belajar di rumah juga dilihat sebagai masalah yang harus mendapatkan perhatian karena berdasarakan hasil penelitian diketahui bahwa banyak orangtua yang belum mengerti tentang sistem pembelajaran daring seperti cara mengerjakan tugas, cara mendapatkan informasi mengerjakan tugas-tugas hingga mengawasi pembelajaran anak-anak dirumah (Rusli, Nio, Akbar \& Nurmina, 2020; Haluan. Com, 2020; Republika.co.id, 2020).

Yusra Tebe mengatakan berdasarkan data UNICEF-RDI, saat ini lebih dari 60 juta siswa di Indonesia tidak dapat bersekolah akibat terdampak Covid-19. Siswa yang paling terdampak adalah siswa tingkat dasar (SD) atau sederajat yaitu lebih dari 28 juta siswa, kemudian siswa SMP atau sederajat sebesar 13 juta siswa, dan siswa SMA atau sederajat berjumlah 11 juta siswa. Berdasarkan data tersebut diketahui masih banyak lagi siswa yang tidak melaksankan belajar. Penyebabnya adalah beberapa daerah belum dapat mengakses internet sementara pembajaran luring (offline) masih dibatasi. Adapun masalah yang sering muncul dari pembelajaran di rumah adalah $69 \%$ anak merasa bosan, sementara 35\% masalahnya akses internet dan 38\% mengalami 
masalah dalam bimbingan belajar oleh guru. Hasil survei menyimpulkan bahwa sebanyak $62 \%$ partisipan berharap mendapatkan akses internet dan 26\% lainnya ingin mendapatkan bimbingan belajar dari guru (Winahyu, 2020).

Persiapan sumber daya manusia (guru) dan siswa diperlukan karena infrastruktur dan fasilitas yang baik saja tidak cukup meningkatkan pembelajaran. Perlu sosialisasi yang masif dan terstruktur untuk menyiapkanya. Diantaranya dapat dilakukan dengan menyediakan dan menyebarkan media-media seperti video tentang buku manual atau cara menggunakan teknologi yang ada. Dillon dan Gunawardena (1995, dalam Bakhtiar, 2020) mengatakan ada faktor yang menentukan efektivitas pembelajaran daring. Pertama, teknologi, yaitu siswa memiliki akses yang mudah menjangkau jaringan secara cepat. Kedua, karakteristik pengaja, yaitu pengajar dapat melaksanakan kegiatan pembelajaran daring dengan efektif. Ketiga, karakteristik siswa, yaitu siswa memiliki kemampuan dalam menggunakan media belajar daring.

Menanggapi belajar di situasi pandemi dimana aktivitas belajar dibatasi, Fahriza Marta Tanjung (Wasekjen Federasi Serikat Guru Indonesia) mengatakan bahwa sekolah perlu menyederhanakan kurikulum, ia menyebutnya dengan kurikulum darurat. Pembelajaran sebaiknya dikelompokkan menjadi bagian literasi, numerasi, sains, pendidikan kecakapan hidup, dan pendidikan karakter. Sementara itu, perlu ditambah jumlah pembelajaran di rumah melalui tayangan TV, misalnya siswa kelas 1 SD dan kelas 2 SD masing-masing satu sesi (Rajab, 2020). Guru juga dapat membuat media pembelajaran audio visual seperti video yang kreatif supaya menarik dan menyenangkan (Murdianto, 2020)

Terkait dengan media pembelajaran. Berdasarkan analisa situasi di tempat mitra, pada umumnya masalah penguasaan media belajar juga dialami oleh sekolah mitra. Berdasarkan hasil wawancara dengan mitra, saat ini siswa telah kembali belajar tatap muka disekolah dengan pengaturan jumlah kehadiran siswa di kelas dan jumlah jam belajar. Artinya, sistem pembelajaran belum dapat dilakukan seperti kurikulum di era normal. Siswa SD ditempat mitra diberi modulmodul oleh guru. Menurut kepala sekolah, guru-guru tidak punya pilihan selain buku dan modul dalam mengajar karena tuntutan orangtua dan kondisi guru yang minim ketrampilan menggunakan media belajar digital. Guru lebih mengandalkan media belajar buku dan pemberian tugas-tugas melalui modul-modul pembelajaran. Orangtua siswa menolak pemberian tugas melalui grup whattsapp sehingga orangtua lebih suka datang langsung ke sekolah menjemput tugas-tugas siswa. Orangtua seringkali mengeluh dengan metode belajar daring era baru di sekolah SDIT MUTIARA Pariaman dengan alasan orangtua menilai anak sulit memahami penugasan belajar melalui whattsap.

Berdasarkan keterangan mitra dirumuskan masalah utamanya adalah sistem pembelajaran di masa era baru tidak maksimal disebabkan oleh beberapa hal, seperti pembatasan jumlah kehadiran siswa dan jumlah belajar siswa. Selain itu pihak sekolah mengalami kesulitan bekerjasama dengan orangtua dalam mendampingi anak belajar dirumah. Orangtua tidak mendukung sistem belajar daring karena khawatir dampak buruk dari mengakses internet. Masalah persepsi orangtua terhadap kekhawatiran bahaya internet terhadap perilaku anak menjadi masalah tersendiri yang menghambat anak dalam memperoleh pengetahuan. Persepsi orangtua diduga berhubungan dengan literasi orangtua terhadap media belajar di masa sekarang. Selain itu, masalah yang tak kalah pentingnya adalah terkait dengan ketrampilan guru menggunakan media belajar digital disekolah. Penguasaan media belajar sangat penting dalam meningkatka motivasi dan hasil belajar siswa (Kartikasari, 2016). Berdasarkan informasi kepala sekolah dari 40 guru, hanya 3 orang guru saja yang biasa menggunakan media belajar digital. Sehubungan dengan minimnya jumlah guru yang memiliki keahlian dalam menggunakan media belajar digital maka sangat penting dilakukan percepatan peningkatan skill guru demi menunjang pembelajaran siswa di masa yang akan datang.

Berdasarkan analisis situasi mitra tersebut, Universitas Negeri Padang ingin melakukan kegiatan pengabdian masyarakat dalam rangka tridharma perguruan tinggi. Bentuk kegiatan PKM 
adalah pembekalan dan pelatihan meningkatkan keahlian guru dalam membuat media belajar digital melalui unit Lembaga Pengabdian Masyarakat.

\section{METODE}

Program Kemitraan Masyarakat (PKM) pelatihan media belajar digital dilaksanakan menggunakan metode antara lain :

a. Subyek Penelitian

Partisipan penelitian adalah 25 guru SDIT Mutiara Pariaman yang direkrut oleh kepala sekolah yang merupakan perwakilan dari setiap kelas. Subyek dalam penelitian terdiri dari guru perempuan (21 orang) dan guru laki-laki (4 orang). Latar belakang pendidikan guru pada umumnya lulusan sarjana (S1). Pendaftaran peserta dilakukan melalui whattsapp grup sekolah.

b. Alat Ukur

Untuk mengetahui pengaruh pelatihan terhadap peningkatan wawasan dan ketrampilan guru menggunakan media belajar digital, diukur menggunakan angket (pretes dan postes) yang disebarkan ke peserta sebelum dan sesudah acara. Angket terdiri dari lima pertanyaan dengan dua pilihan respon atau jawaban ya/tidak (Rusli, dkk, 2020; Barovih, Ardiansyah, \& Hutanegara, 2021). Kuesioner diisi oleh guru yang disebar sebelum dan sesudah kegiatan pelatihan. Adapun Item-item pertanyaannya dapat dilihat pada tabel 1 berikut :

Tabel 1. Kuesioner Pelatihan Media Belajar Digital

\begin{tabular}{llll}
\hline No & \multicolumn{1}{c}{ Pertanyaan } & Ya & Tidak \\
\hline 1. & $\begin{array}{l}\text { Saya tahu jens-jenis media belajar digital seperti video, youtube dll } \\
\text { 2. }\end{array}$ & $\begin{array}{l}\text { Saya memahami peran media belajar digital terhadap keberhasilan } \\
\text { belajar siswa }\end{array}$ & \\
3. & $\begin{array}{l}\text { Saya tahu langkah-langkah membuat media belajar digital seperti video } \\
\text { 4. }\end{array}$ & $\begin{array}{l}\text { Saya tahu syarat-syarat dalam membuat media belajar digital seperti } \\
\text { video yang menarik }\end{array}$ & \\
5. & Saya bisa membuat dan mengedit video belajar yang lebih menarik & \\
\hline
\end{tabular}

c. Prosedur Kegiatan

Kegiatan PKM dilangsungkan tanggal 19-21 Agustus 2021 dimulai dari survei kebutuhan mitra hingga pelaksaan acara. Penjelasan prosedur PKM sebagai berikut:

1. Persiapan Kegiatan

Tanggal 19 Agustus 2021, panitia PKM melakukan survei awal untuk melakukan analisis kebutuhan dari mitra. Tim panitia berkenalan dengan pihak kepala sekolah dan guru-guru dalam rangka sosialisasi kegiatan PKM. Ketua panitia dan melakukan wawancara dengan tentang media pembelajaran daring yang digunakan oleh guru-guru selama ini. Setelah menemukan masalahnya ketua panitia melakukan pertemuan dengan tim panitia untuk persiapan kegiatan PKM seperti desain brosur, bentuk kegiatan, menyusun kuesioner pre-pos tes, rundown kegiatan, teknis seleski peserta dan sebagainya.

2. Pelaksanaan Kegiatan

Pretest dan post-test diselenggarakan tanggal 21 Agustus 2021 secara luring sebelum dan sesudah kegiatan pelatihan. Setelah pre-post test tim melakukan proses checking, skoring dan input data peserta. 


\section{HASIL DAN PEMBAHASAN}

Kegiatan pelatihan diselenggarakan secara luring dengan menerapkan protokol kesehatan sesuai yang dianjurkan oleh pemerintah. Namun demikian sosialisasi kegiatan dilakukan melalui brosur yang disebar oleh panitia di grup whattsapp calon peserta.

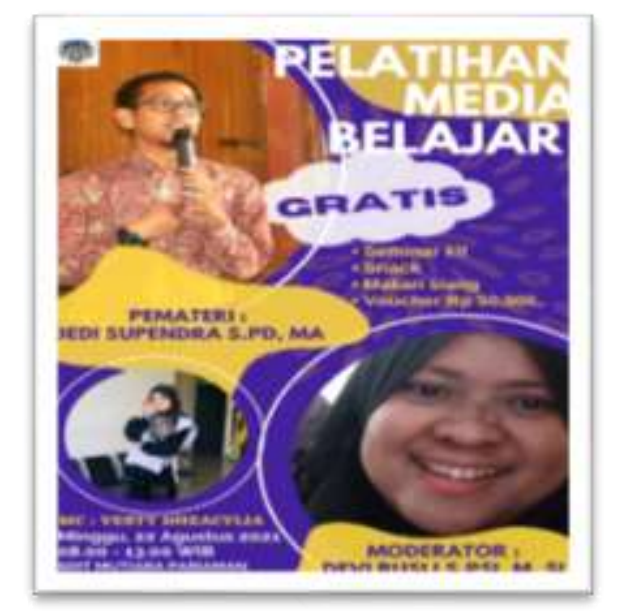

Gambar 1. Brosur Acara Peserta Pelatihan

Pada hari pelaksanaan, semua peserta mendapatkan materi tentang media belajar digital yang disampaikan oleh pemateri Bapak Dedi Supendra, S. Pd, MA dengan moderator acara Ibu Devi Rusli, S. Psi, M. Si. Materi tersebut penting bagi peseerta untuk membuka wawasannya tentang peran media belajar menunjang pembelajaran siswa selama belajar daring dan pemeblajaran di masa yang akan datang. Setelah penyampaian materi, dibuka sesi diskusi dimana peserta diberi kesempatan bertanya tentang media pembelajaran digital. Pemateri memotivasi peserta agar guru-guru semangat belajar menggunakan aplikasi digital dalam membuat media pembelajaran yang menarik.

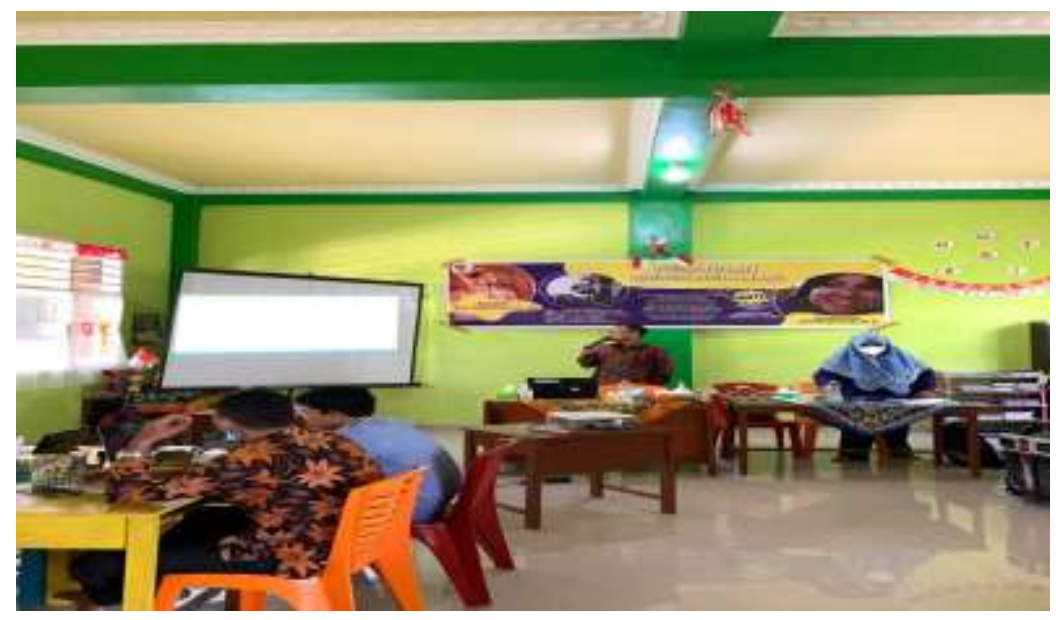

Gambar 2. Moderator Memandu Pemateri

Setelah presentasi materi, kegiatan dilanjutkan dengan workshop yang dipandu oleh Bapak Dedi Supendra, S.Pd, MA yang berlangsung selama 90 menit. Peserta antusias mengikutinya,hal ini karena mereka ingin mempraktekkan langsung cara menggunakan aplikasi video pembelajaran yang diajarkan oleh pelatih. Sebelumnya pelatih mengajarkan cara mendowload aplikasi, memperkenalkan tools dalam aplikasi dan membuat video yang menarik berdasarkan koleksi video yang dimiliki oleh guru-guru. Peserta dibagi dalam beberapa kelompok agar fokus mengerjakan video pembelajaran. Setelah 90 menit kegiatan, terdapat beberapa kelompok berhasil mempraktekkan pembuatan video pembelajaran menggunakan 
aplikasi filmora. Setelah 3 jam sesi presentasi dan workshop, selanjutnya acara foto bersama pemateri, peserta dan panitia. Kemudian, acara penutup, ketua panitia (Devi Rusli, S. Psi, M. Si) menyampaikan ucapan terimakasih kepada mitra, guru-guru, dan pemateri yang telah berpartisipasi dalam menyukseskan kegiatan pelatihan.

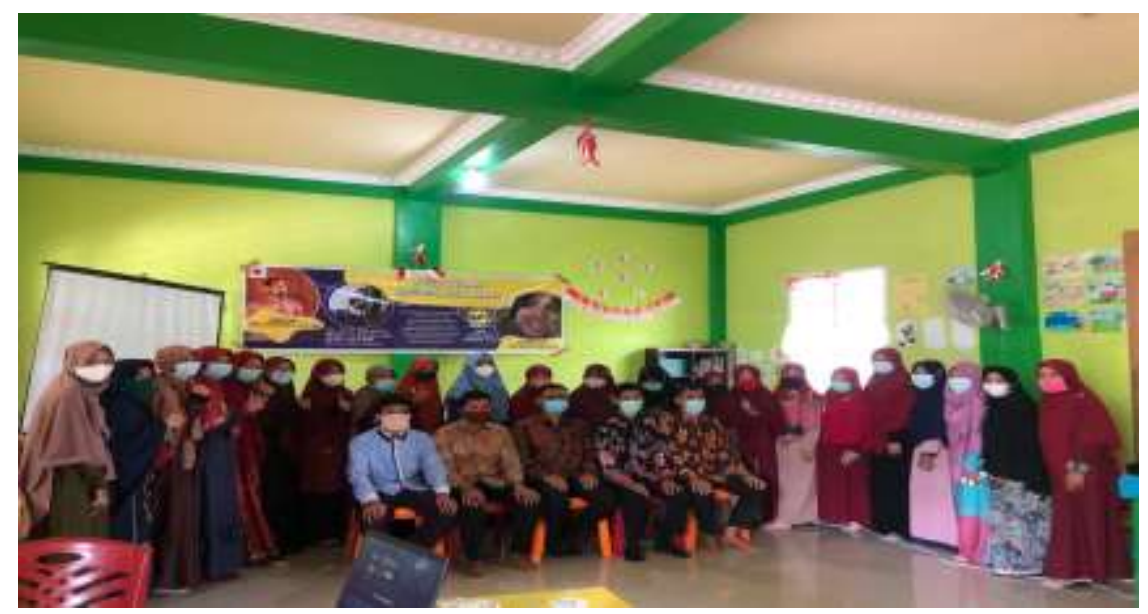

Gambar 4. Foto Bersama

Hasil survei sebelum dan sesudah pelaksanaan kegiatan pelatiahn media belajar digital dapat dilihat dari hasil pre-test dan post-test pada tabel 2. Pada tabel 2 dapat dilihat bahwa sebelum dilaksankan pelatihan 63,85\% partisipan mengerti cara menggunakan media belajar digital, sedangkan setelah pelatihan 99, 23\% partisipan dapat memahami cara menggunakan media belajar digital. Berdasarkan tabel 2 dapat diketahui bahwa wawasan guru mengenai media pembelajaran digital sebelum dan sesudah pelatihan berbeda. Artinya pelatihan media belajar digital efektif meningkatkan wawasan dan ketrampilan guru dalam menggunakan media belajar digital di masa new normal.

Tabel 2. Hasil Sebelum dan Sesudah Pelatihan

\begin{tabular}{cccccccc}
\hline No & Partisipan & Pretes & Postes & No. & Partisipan & Pretes & Postes \\
\hline 1 & Nisa & 5 & 5 & 14 & Rini & 2 & 5 \\
2 & Sumiarti & 5 & 5 & 15 & Willy & 2 & 5 \\
3 & Desi & 5 & 5 & 16 & Silvia & 4 & 5 \\
4 & Riska & 4 & 5 & 17 & Astri & 4 & 5 \\
5 & Anita & 2 & 5 & 18 & Nia & 3 & 5 \\
6 & Karnilawati & 2 & 5 & 19 & Dedet & 5 & 5 \\
7 & Asri & 3 & 5 & 20 & Ari & 4 & 5 \\
8 & Yosia & 3 & 5 & 21 & Herman & 2 & 5 \\
9 & Leni & 1 & 5 & 22 & Fariza & 3 & 5 \\
10 & Intan & 2 & 5 & 23 & M.Afiy & 5 & 5 \\
11 & Irnawati & 2 & 5 & 24 & Hilda Fitria & 5 & 5 \\
12 & Titit & 2 & 4 & 25 & Azwirda A & 3 & 5 \\
13 & Nada & 2 & 5 & 26 & Yasmainisa & 3 & 5 \\
& & \multicolumn{7}{c}{ JUMLAH } & & & $88(63.85 \%)$ & $129(99,23 \%)$ \\
\hline
\end{tabular}

\section{KESIMPULAN}

Setelah dilaksanakan program kemitraan masyarakat dalam bentuk pengayaan dan pelatihan penggunaan media belajar digital terhadap guru-guru SDIT MUTIARA di Pariaman, maka berdasarkan hasil kegiatan dapat disimpulkan bahwa: 

1) Guru memperoleh wawasan mengenai peran media pembelajaran dalam mendukung pembelajaran daring.
2) Guru memiliki wawasan tentang berbagai macam media yang dapat digunakan dalam pembelajaran daring.
3) Guru mendapatkan pengalaman tentang cara mengedit video pembelajaran yang menarik.
4) Guru mempraktekktan ketrampilan menciptakan video pembelajaran yang menarik dengan memanfaatkan aplikasi filmora.

\section{UCAPAN TERIMA KASIH}

Penulis menyampaikan pengahargaan yang tinggi dan terima kasih kepada Lembaga Penelitian dan Pengabdian Masyarakat (LP2M) Universitas Negeri Padang, Sumatera Barat yang telah membiayai penelitian ini dengan nomor kontrak : 1242/UN35.13/PM/2021

\section{DAFTAR PUSTAKA}

Bahtiar. F (2020). Sindo.com. "FSGI Sebut Masalah Pjj Hingga Kini Tak Bisa Diatasi. https://edukasi.sindonews.com/read/217158/212/fsgi-sebut-masalah-pjj-hingga-kini-takbisa-diatasi-1604308300

Barovih. G., Ardiansyah. M. R., \& Hutanegara.D. A. (2021). Penggunaan Google Classroom Bagi Guru Sekolah Dasar Negeri 170 Palembang Sebagai Platform Pembelajaran Daring di Masa Pandemi Covid-19. Dinamisia : Jurnal Pengabdian Kepada Masyarakat, 5(4). https://doi.org/10.31849/dinamisia.v5i4.7148

Haluan,com. (2020, Maret 24). "Keluh Kesah Orang Tua dengan Belajar Online saat Corona mewabah"https://www.harianhaluan.com/news/detail/90365/keluh-kesah-orangtuadengan-belajar-o nline-saat-corona-mewabah.

Kartikasari, G. (2016). Pengaruh Media Pembelajaran Berbasis Multimedia Terhadap Motivasi Dan Hasil Belajar Materi Sistem Pencernaan Manusia: Studi Eksperimen pada Siswa Kelas V MI Miftahul Huda Pandantoyo. Dinamika Penelitian: Media Komunikasi Penelitian Sosial Keagamaan, 16(1), 59-77. https://doi.org/10.21274/dinamika.2016.16.1.59-77

Murdianto, M. T. (2020). Peran Teknologi Video dalam Mendukung Pendidikan di Masa Depan. https://www.idntimes.com/life/education/muhammad-tarmizi-murdianto/peranteknologi-video-dalam-mendukung-pendidikan-di-masa-depan $/ 5$

Rajab. M. (2020). Detik.Com. Evaluasi Dan Optimalisasi Pembelajaran Daring https://news.detik.com/kolom/d-4960905/evaluasi-dan-optimalisasi-pembelajaran-daring

Republika.co.id. (2020). "Murid Belajar di Rumah: Stres Orang Tua dan Kendala Lainnya” diambil dari https://republika.co.id/berita/q7dlrn409/murid-belajar-di-rumah-stresorang-tua-dankendala-lainnya

Rusli, D., Nio, S. R., Akbar \& Nurmina. (2020). Psikoedukasi Online Pendampingan Anak Belajar Daring Akibat Terdampak Pandemi Covid 19. Jurnal Pelayanan Kepada Masyarakat (PLAKAT), 2(2), 167-181.

Sandi, E. D. (2020). Kompas.Com. "Mengatasi Masalah Jaringan Internet Pjj Dengan One Teacher One" https://www.kompas.com/edu/read/2020/11/11/163544071/mengatasi-masalahjaringan-internet-pjj-dengan-one-teacher-one-server

Winahyu. A.I (2020). Dampak Pandemi Kualitas Pendidikan Alami Penurunan. https://mediaindonesia.com/humaniora/321039/dampak-pandemi-kualitas-pendidikanalami-penurunan

Zahralubis728. (2020). Kumparan.Com. Minimnya Akses Internet saat Pembelajaran Daring di Daerah Terpencil. https://kumparan.com/zahralubis728/minimnya-akses-internet-saatpembelajaran-daring-di-daerah-terpencil-1uUuXFLeQsv 